\title{
Two Dimensional Flows on Degree of Porosity and Permeability Influences on Radial Flow in Lateritic and Silty Formation Patani Coastal Area of Niger Delta
}

\author{
Eluozo S. N. \\ Department of Civil and Environmental Engineering, Subaka Nigeria Limited Port Harcourt, Port Harcourt, Nigeria
}

Email address:

soloeluozo2013@hotmail.com, solondu2015@yahoo.com

\section{To cite this article:}

Eluozo S. N. Two Dimensional Flows on Degree of Porosity and Permeability Influences on Radial Flow in Lateritic and Silty Formation Patani Coastal Area of Niger Delta. International Journal of Industrial and Manufacturing Systems Engineering.

Vol. 2, No. 2, 2017, pp. 7-10. doi: 10.11648/j.ijimse.20170202.11

Received: September 30, 2016; Accepted: February 10, 2017; Published: April 4, 2017

\begin{abstract}
This paper is monitor the deposition of radial flow applying deterministic modelling techniques, the system observed porosity and permeability to express lots of influences determined by geological setting from the soil. This expression were found imperative on the system in other to ensure that two dimensional phase of radial flowstudy are carried out. Permeability and porosity influences were observed to pressure it deposition in various soil formation in lateritic and silty formation. The influences are from the structural disintegration from porous rocks, the rates of permeation were observed to be paramount parameters deposited in two dimensional flow phase of the system. Investigation carried out express these stated parameters as one of the formation influences that may have pressured the variation of radial flow in lateritic and silty formation. The developed modelling approach were found imperative, the expressed model were generated base on the developed system through these variables, experts in soil engineering will applied these concepts as one way to monitor two dimensional radial flow in unconfined bed including other engineering purpose.
\end{abstract}

Keywords: Two Dimensional Flow, Porosity, Permeability Lateritic, Silty Formation and Radial Flow

\section{Introduction}

Most of stabilization has to be undertaken in soft soils (silty, clayey peat or organic soils) in order to achieve desirable engineering properties. According to Sherwood George [1] fine-grained granular materials are the easiest to stabilize due to their large surface area in relation to their particle diameter. A clay soil compared to others has a large surface area due to flat and elongated particle shapes. On the other hand, silty materials can be sensitive to small change in moisture and, therefore, may prove difficult during stabilization [1, 2, 3 and 4]. Peat soils and organic soils are rich in water content of up to about $2000 \%$, high porosity and high organic content. The consistency of peat soil can vary from muddy to fibrous, and in most cases, the deposit is shallow, but in worst cases, it can extend to several meters below the surface [5, 6, 7 and 8]. Organic soils have high exchange capacity; it can hinder the hydration process by retaining the calcium ions liberated during the hydration of calcium silicate and calcium aluminates in the cement to satisfy the exchange capacity. In such soils, successful stabilization has to depend on the proper selection of binder and amount of binder added [9, 10, and 11]. Particle size and shape reflect material composition, grain formation and release from the mineral matrix, transportation, and depositional environments. Mechanical and chemical processes determine grain shape once it is released from the matrix [11 and 12]. The transition region from chemical to mechanical shape-control occurs for a particle size between $\mathrm{d} \sim 50$-to-400 $\mu \mathrm{m}$. Chemical action and abrasion increase with age and older sands tend to be rounder regardless of particle size. The larger the particle the higher the probability of imperfections and brittle fracturing (typically $\mathrm{d}>400 \mu \mathrm{m}$ ). Conversely, smaller particles are stronger by lack of imperfections, then, failure by cleavage along crystal atomic planes becomes energetically advantageous and the resulting particles are more platy [10, 13 and 14]. Particle shape is characterized by three dimensionless ratios [9, 10 and 11]: sphericity $S$ (cf. eccentricity or platiness), roundness $R$ (cf. angularity) and smoothness (cf. roughness). Sphericity 
indicates whether one, two, or three of the particle dimensions are of the same order of magnitude, and it is defined as the diameter of the largest inscribed sphere relative to the diameter of the smallest circumscribed sphere Roughness describes the surface texture relative to the radius of the particle. Spehericity, roundness and smoothness form an independent set. While spehericity and roundness increase by abrasion, they do not increase proportionally. Furthermore, chipping of a particle may increase the sphericity, but it decreases the roundness [8]. Sphericity and roundness can be effectively characterized by visual comparison with charts [6, 7]. Digital image analysis facilitates the evaluation of mathematical descriptors of particle shape including Fourier analysis, fractal analysis and other hybrid techniques [6, 7, 9, 13, and 14].

\section{Theoretical Background}

However, the process of eliminating water from a vertical well imposes a particular geometry on the round-water flow pattern in the vicinity of the well called radial flow. These is a method ofpumping wellstrongly converging flow whose geometry may be described by a particular family of differential equations that utilize cylindrical coordinates $(\mathrm{R}$, Z) instead of Cartesian coordinates. A large number of analytical solutions to these differential equations with different boundary conditions. These describe the distribution of head near a pumping well. To obtain water from groundwater system, wells are installed and pumped. Water pumped from the Well lowers the water level in the well, thereby establishing a head gradient from the aquifer toward the well. As a result, water moves from the surrounding aquifer into the well. As pumping proceeds, adecline in head or drawdown propagates away from the well as water continues to move from areas of higher head to areas of lower head and ispumped out of the well. The deposition of radial flow were observed to be pressure byporosity, thereareseveral structured strata base on thegeological setting in thearea, the studyof porosity influences through radial flow influences can be monitored through hydraulic conductivity base on the permeation of the formation. But for yield rate from velocity will definitely pressure itin several dimension, experts in various conceptualize approach has monitored radial flows through permeation of the structural setting of their area of study. The depositions of soil porosity are basically depending on the rate of disintegration from porous rock structured, these are in a condition were it will influenced the radial flow in confined and unconfined beds. Thisinclude other mineral of natural origin, it has been observed that variations of porosity degree and permeability is the most region effect in deltaic formations. The effect of porosity permeability on radial flows are also observed to influencessoil bearing capacity, these are also reflected on these basic formation of soil at various depth and location, these study look at the engineering properties of soil including heterogeneous deposition of the formation characteristics, baseon these variances in deposition of the formation characteristics, it was imperative to monitored the radial flow in two dimensional phase. Furthermore several challenges from soil developed circumstances such as collapsible of soils, these are known to determine the ability of soils susceptible to express hydro consolidation, they are geologically young, unconsolidated, low-density, loose, more so dry soils, it is commonly present in arid to semi-arid regions. These soils generally occur within the top 10 to 15 feet of wind deposited sands or silts (loess), alluvial fans, colluvial soils, stream banks or residual mudflow soils. Collapsible soils have granular particles that are supported by clay or silt and can be chemically cemented in place creating a porous structure. The bonds supporting this porous structure generally has enough shear strength to support loads, however once water is introduced, the porous structure collapses and the granular particles are re-arranged. Foundation systems on collapsible soils condition shall be constructed in a manner that will minimize damage to the structure caused by hydro-consolidation settlements.

\section{Governing Equation}

$$
K \frac{\partial \phi_{(x)}}{\partial z}=D v_{(x)} \frac{\partial \phi}{\partial x}+V_{(x)} \frac{\partial \phi}{\partial x}
$$

The developed governing is expressed to monitor the prediction of porosity and permeability on two dimensional phases in the study locations. The system integrates parameters that pressured the degree of porosity and permeability at various depositions. The expressed governing equations are developed in such a way that it will be thoroughly monitor the system in two dimension, these will be achieved through the derivedsolution considering several conditions in itdeposited formation

Nomenclature

$\mathrm{K}=$ Permeability $\left[\mathrm{LT}^{-1}\right]$

$\phi=$ Radial Flow [-]

$\mathrm{D}=$ Dispersion in number [-]

$\mathrm{V}(\mathrm{x})=$ Velocity $\left[\mathrm{LT}^{-1}\right]$

$\mathrm{Z}=$ Depth [L]

$\mathrm{X}=$ Depth $[\mathrm{L}]$

Let $\phi=X Z$ from equation (2), we have

$$
\begin{gathered}
K Z^{1} Z=D_{v} Z X^{1}+V_{(x)} Z X^{1} \\
K \frac{Z^{1}}{Z}=D_{v} \frac{X^{1}}{X}+V_{(x)} \frac{X^{1}}{X} \\
K \frac{Z^{1}}{Z}=\tau^{2} \\
D_{v} \frac{X^{1}}{X}=\tau^{2} \\
V_{(x)} \frac{X^{1}}{X}=\tau^{2}
\end{gathered}
$$

This implies that equations (5) and (6) can be written as: 


$$
\left[D_{v}+V_{(x)}\right] \frac{X^{1}}{X}=\tau^{2}
$$

From (4) $K \phi \frac{Z^{1}}{Z}=\tau^{2}$

$$
\begin{aligned}
& \text { i.e. } K \frac{d Z}{d Z}=\tau^{2} \\
& \begin{array}{c}
\int \frac{d Z}{Z}=\frac{\tau^{2}}{K \phi} \int d z \\
\operatorname{Ln} Z=\frac{\tau^{2}}{K \phi} z+c_{1} \\
L n Z=\frac{\tau^{2}}{K \phi}+c_{1} \\
Z=A \ell^{\frac{\tau^{2}}{K \phi}}
\end{array}
\end{aligned}
$$

Since the influences on permeability and porosity are basically from velocity on radial flow, the study will definitely be monitoredfrom other development that took place within the system under dynamic conditions. The consideration of vertical flow direction are base on the facts that radial flow express it under the influences of permeability through velocity on two dimensional phase of the formation, such derived solutionrelate theexpression in [12] to monitor movement of fluid under the influence of velocity in two dimensional condition of fluid flow in the strata, these condition were considered in the system that generated model with respect to vertical direction of flow.

From (6)

$$
\begin{gathered}
{\left[D_{v}+V_{(x)}\right] \frac{X^{1}}{X}=\tau^{2} d x} \\
\int \frac{d x}{x}=\frac{\tau^{2}}{D_{v}+V_{(x)}} \int d x \\
\operatorname{Ln} x=\frac{\tau^{2}}{D_{v}+V_{(x)}} X+c_{1} \\
Z=\exp \left[\frac{\tau^{2}}{D_{v}+V_{(x)}} X+c_{1}\right] \\
X=B \exp \frac{\tau^{2}}{D_{v}+V_{(x)}} x
\end{gathered}
$$

Combining (17) and (18), we have

$$
C, Z X=Z X
$$

$$
\begin{gathered}
A e \frac{\tau^{2}}{K} Z B\left[\exp \frac{\tau^{2}}{D_{v}+V_{(x)}}\right] \\
C X, Z=A B \exp \left[\frac{Z}{K}+\frac{X}{D_{v}+V_{(x)}}\right] \tau^{2}
\end{gathered}
$$

The developed model for radial flow under the influences of porosity and permeability in two dimensional phases has been expressed in twenty; the developed system will definitely predict radial flow under the influences of porosity and permeability in lateritic and silty formation. Thestudy expresses several conditionsthat radial flows are influenced by permeability and porosity at various dimensions. The two dimensional flow through permeability and porosity from pore size distribution characterize on its pore space, such portion of the soil's volume were observed not to be occupied or isolated by solid material. The pore space has fluid pathways that are tortuous, variably constricted, and usually highly connected. The pore space is often considered in terms of individual pores--an artificial concept that enables quantifications of its essential characteristics.

\section{Conclusion}

Radial flow has been monitored in several conditions throughmodeling approach, the system express various formation variables that affect the rate of radial flow in the study area, it has been observedthatporosity and permeability developed serious influences in the system; the developed governing equation consider predominant formation characteristics in differentgeological setting. More so, the effects from engineering properties were also stressed to generate the derived model for the study. Furthermore, porosity degree are base on the type of grain size, thus, Porosity $\varphi$ is the fraction of the total soil volume that is taken up bypore space. The relationship between porosity and permeability expressed the pressured from two dimensional flow, it has been observed that porosity are through a single-value quantification of the amount of space available to fluid within a specific body of soil; the deposition of radial flow through hydraulic gradient express the significant effect from porosity, it is often conceptually partitioned into two components, inmost condition it is commonly called textural and structural porosity. The study has applied this concept to monitor the pressure from porosity and permeability on the radial flow in the study area.

\section{References}

[1] Bowman, E. T., Soga, K., and Drummnond, W. (2001). "Particle shape characterization using Fourier descriptor analysis." Géotechnique, 51 (6), 545-554.

[2] Barrett, P. J. (1980). "The shape of rock particles, a critical review." Sedimentology, 27, 291-303. 
[3] Clark, N. N. (1987). "A new scheme for particle shape characterization based on fractal harmonics and fractal dimensions." Powder Technology, 51, 243-249.

[4] Folk, R. L. (1955). "Student operator error in determination of roundness, sphericity, and grain size." Journal of Sedimentary Petrology, 25 (4), 297-301.

[5] Krumbein, W. C. (1941). "Measurement and geological significance of shape and roundness of sedimentary particles." Journal of Sedimentary Petrology, 11 (2), 64-72.

[6] Krumbein, W. C. and Sloss, L. L. (1963). Stratigraphy and Sedimentation, Second Edition, W. H. Freeman and Company, San Francisco, 660 pages.

[7] Hyslip, J. P. and Vallejo, L. E. (1997). "Fractal analysis of the roughness and size distribution of granular materials." Engineering Geology, 48, 231-244.

[8] Meloy, T. P. (1977). "Fast Fourier transforms applied to shape analysis of particle silhouettes to obtain morphological data." Powder Technology, 17, 27-35.

[9] Powers, M. C. (1953). "A new roundness scale for sedimentary particles." Journal of Sedimentary Petrology, 23 (2), 117-119.

[10] Rahaman, M. N. (1995). Ceramic Processing and Sintering, Dekker Inc., NY, 770 pages.

[11] Sukumaran, B., and Ashmawy, A. K. (2001). "Quantitative characterization of the geometry of discrete particles." Géotechnique, 51 (7), 171-179.

[12] Gye-Chun Cho, Jake Dodds, and J. Carlos SantamarinaParticle Shape Effects on Packing Density, Stiffness and Strength-Natural and Crushed Sands-Residential code 2011 manual county of Los Angeles department of public works building and safety division based on the 2011 lacrc.

[13] Nimmo J. R 2004 Porosity and Pore Size Distribution Hillel, D., ed. Encyclopedia of Soils in the Environment: London, Elsevier, v. 3, p. 295-303.

[14] U. S. geological survey open-file Report 90- 183 study guide for a beginning-g course in ground-water hydrology: part i -course participants. 